\title{
Performance Pay, Delegation and Multitasking under Uncertainty and Innovativeness An Empirical Investigation
}

\author{
Foss, Nicolai J.; Laursen, Keld
}

Document Version

Final published version

Publication date:

2002

License

CC BY-NC-ND

Citation for published version (APA):

Foss, N. J., \& Laursen, K. (2002). Performance Pay, Delegation and Multitasking under Uncertainty and Innovativeness: An Empirical Investigation. DRUID - Danish Research Unit for Industrial Dynamics. DRUID Working Paper No. 02-14

Link to publication in CBS Research Portal

\footnotetext{
General rights

Copyright and moral rights for the publications made accessible in the public portal are retained by the authors and/or other copyright owners and it is a condition of accessing publications that users recognise and abide by the legal requirements associated with these rights.

Take down policy

If you believe that this document breaches copyright please contact us (research.lib@cbs.dk) providing details, and we will remove access to the work immediately and investigate your claim.
} 


\section{$\mathbf{D}_{\text {ANSH }} \mathbf{R}_{\text {ESearch }} \mathbf{U}_{\text {NIt foR }} \mathbf{I}_{\text {NDUStrial }} \mathbf{D}_{\text {YNaMics }}$}

DRUID Working Paper No 02-14

Performance Pay, Delegation, and

Multitasking under Uncertainty and Innovativeness: an Empirical Investigation

by

Nicolai J. Foss and Keld Laursen 


\title{
Performance Pay, Delegation, and Multitasking under Uncertainty and Innovativeness: An Empirical Investigation
}

\author{
Nicolai J. Foss and Keld Laursen \\ Department of Industrial Economics and Strategy, \\ Copenhagen Business School, Solbjergvej 3, 2000 Frederiksberg, Denmark \\ E-mail: njf.ivs@cbs.dk, kl.ivs@,cbs.dk
}

\begin{abstract}
The existing empirical evidence is somewhat inconclusive with respect to a number of the key predictions of the agency model. Although the reach of agency theory is considerably wider, the dominant portion of work has been taken up with examining the nature of the trade-off between risk and incentives, and the implications thereof for contractual design. More specifically, some researchers have recently noted that the predicted trade-off between risk and incentives turns out to be rather weak, and perhaps non-existent, when confronted with the available empirical evidence. In this paper, we examine the risk-incentives trade-off and related predictions from agency theory on the basis of data from a data set encompassing close to 1000 Danish firms. We find that the relation between the use of performance pay in these firms and the environmental uncertainty they confront - which is one way to test the risk/incentives tradeoff — is indeed weak and in many cases even perverse. We then suggest, in line with other recent contributions to the literature, that this may be caused by the widespread use of delegation. One effect of delegation is that it breaks the simple relation between risks and incentives. We examine the suggestion that that those firms that are more prone to use delegation of decision rights in their internal organization are facing an uncertain environment to a larger extent than the rest of the population. We argue that this constitutes an indirect confirmation of the hypothesis. We also examine the multi-tasking agency hypothesis that as risk increases, the flexibility of agents is restricted. We fail to find support for this hypothesis. It is suggested that the reason for this finding is also related to delegation.
\end{abstract}

Key words: Uncertainty, pay-for-performance, delegation, innovation, competition

JEL Codes: C35, L23

\section{Acknowledgments}

The comments of Brian Silverman and Nick Argyres on an earlier version of this paper are gratefully acknowledged. In addition, we wish to thank the participants in the DISKO project at Aalborg University for allowing us to use the data applied in this paper. The usual disclaimer applies. 


\section{Introduction}

Empirical work in agency theory is relatively scant, at least when compared to the abundance of theoretical papers that have appeared since the mid-nineteen-seventies (Masten and Saussier, 2002), and to the rather large and cumulative body of empirical work in related areas, notably transaction cost economics (Shelanski and Klein, 1995). Moreover, the existing empirical evidence is somewhat inconclusive with respect to a number of the key predictions of the agency model. Although the reach of agency theory is considerably wider, the dominant portion of the extant empirical work has been taken up with examining the nature of the trade-off between risk and incentives, and the implications thereof for contractual design, including the design of organizations and institutions. However, as Prendergast $(1999 ; 2000)$ notes, the empirical relation between risk and incentives is "tenuous." Many, perhaps most, other predictions from agency theory have not been subjected to empirical scrutiny. For example, multi-tasking agency theory (Holmström and Milgrom, 1991) predicts that an agent's flexibility (i.e., the number of tasks that he is allowed to engage in) will be restricted, the less reliable the performance measures for his main tasks become. Increasing environmental uncertainty may produce this effect. This prediction has, to our knowledge, never been tested. ${ }^{1}$

In this paper, we undertake to examine the risk-incentives trade-off on the basis of data from a data set encompassing close to 1000 Danish firms. We find that the relation between the use of performance pay in these firms and the uncertainty they confront which is one way to test the risk/incentives tradeoff — is indeed "tenuous." We then suggest, in line with, for example, Jensen and Meckling (1992), Mendelsson and Pillai (1999), and Prendergast (2000) that this may be caused by the widespread use of delegation. An effect of delegation is breaking the simple relation between risks and incentives. We move on to examine indications that suggest that firms that are more prone to use delegation of decision rights in their internal organization are also those firms that face a more uncertain environment than the rest of the population. We argue that this constitutes an indirect confirmation of the hypothesis. We also examine the multitasking agency hypothesis that as risk increases, the flexibility of agents is restricted (Holmström and 
Milgrom, 1991). We fail to find support for this hypothesis. We suggest that the reason for this finding is also related to the issue of delegation.

\section{Theory and Hypotheses}

\section{Basic Agency Theory}

We here briefly and simply restate the basics of the agency model (following the now standard model of Holmström and Milgrom, 1991). Consider a "task" with output, x. x depends on the agent's effort, e, and a normal error term, $\varepsilon$, which has mean, $\mu$, and variance, $\sigma^{2}$, so that $\mathrm{x}=\mathrm{e}+\varepsilon . \mu, \sigma^{2}$ and $\mathrm{x}$ are common knowledge for the agent who and principal. e is unobservable to the principal and $\sigma^{2}$ is uncontrollable for the agent. $\mathrm{x}$ is verifiable, so that contracts, $\mathrm{s}(\mathrm{x})$, specifying the payment from principal to agent can be (costlessly) written. The agent's preferences may be described by the exponential utility function, $-\exp [-\mathrm{r}(\mathrm{s}(\mathrm{x})-\mathrm{c}(\mathrm{e}))]$, where $\mathrm{r}$ is the coefficient of risk aversion and $\mathrm{c}(\mathrm{e})$ is the agent's cost function.

In the standard formulation, the principal's problem is to choose s so that the agent puts effort forward and is not overly burdened with risk. Under certain assumptions (stated in Holmström and Milgrom, 1987), the second-best contract takes a linear form, $s(x)=\alpha x$ $+\beta$, where $\alpha$ is a measure of how "high-powered" incentives are and $\beta$ is simply an income transfer from the principal to the agent (which serves to satisfy the participation constraint). Maximizing the certainty equivalent of joint surplus, which is $u+\mu-1 / 2 \mathrm{r}^{2} \sigma^{2}-\mathrm{c}$ (e), subject to the agent's first order condition, $\mathrm{c}^{\prime}(\mathrm{e})=\alpha$, yields the best choice of $\alpha$. Holmström (1989) gives the example of assuming $\mathrm{c}(\mathrm{e})=1 / 2 \mathrm{ke}^{2}$, which yields $\alpha=\left(1+\mathrm{kr}^{2}\right)^{-1}$. Inspection of this expression reveals that the agent receives a higher share, the lower his aversion to risk is and vice versa ( $\alpha$, the "piece rate," and $r$, the coefficient of risk aversion varies inversely), and that incentives $(\alpha)$ and variance $\left(\sigma^{2}\right)$ also vary inversely. This is the tradeoff between risk-sharing and provision of incentives to supply effort.

The standard model may be extended in various ways, notably by introducing monitoring considerations. In the above setting, higher risk leads to more monitoring,

\footnotetext{
${ }^{1}$ At least directly. Holmström and Milgrom (1991) invoke earlier work by Anderson (1985) and Anderson and
} 
because higher risk leads to a fall in $\alpha$, which in turn reduces effort, prompting an increase in monitoring. The provision of incentives may also be influenced by changing the agent's opportunity costs, that is, controlling which other activities he can engage in, for how long time, etc. Intuitively, the less restricted an agent is - that is, the more discretion he has with respect to his choice of which activities to engage in and for how long - the more costly it is to induce him to work on a specific project. Consequently, the costs of providing incentives may be reduced by restricting the set of activities that an agent is allowed to work on (Holmström and Milgrom, 1990). The costs of measuring the agent's performance in the various activities play a key role for how much the agent will be restricted, as clarified by Holmström and Milgrom (1991). A key prediction from their multitask-agency model is that the more costly it is to measure the agent's performance in his main activities, the more his flexibility will be restricted. Since risk and measurement cost can reasonably be assumed to correlate directly, this train of thought would seem to predict that as risk increases, the agent will tend to become increasingly constrained. An interpretation is that activities will tend to be clustered in those activities that are easily measurable, and those that are not; different kind of incentives will be provided for each.

\section{Empirical Work}

In agency theory, environmental uncertainty has the effect of adding observation error (increase measurement cost) to performance measures (Holmström, 1979; Holmström and Milgrom, 1991; Prendergast, 2000). This increases the risk that is imposed on agents. Hence, the testable prediction is that risk and performance pay correlate negatively. However, as Prendergast (2000) documents at length, this prediction has not fared quite well in the face of the empirical evidence. Specifically, he considers the empirical evidence for the four classes of occupation of executives, sharecroppers, franchisees, and salesforce workers. In the case of executive compensation, the evidence is "inconclusive," although there is weak evidence for relative performance evaluation, an implication of the risk/incentives tradeoff. For sharecroppers, the fraction that they retain turns out to be increasing in the noisiness of financial returns that is directly counter to the agency prediction. Evidence from franchising studies suggest that the choice of whether to keep outlets in-house or franchise them is influenced by uncertainty in a direction opposite to the prediction of agency theory, that is, the probability of choosing franchising is positively

Schmittlein (1984) as indirectly yielding empirical support for their multitask agency model. 
influenced by environmental uncertainty. The evidence on salesforce integration is inconclusive. In sum, the empirical evidence would, on balance, seem to indicate that uncertainty and incentives are positively, rather than negatively, related. This directly contradicts the basic agency model.

\section{Resolving the Uncertainty/Performance Relation}

A strong candidate for explaining why the basic agency prediction seems to be falsified in the light of the empirical evidence is that basic agency theory fails to consider the many benefits of delegation (Foss and Foss, 2002). Indeed, in the basic story, the only benefit of delegation seems to be economizing with the opportunity costs of the principal's time. If these were low or zero, the principal would carry out the task himself, particularly since differences in knowledge about how to optimally carry out the task do not seem to exist.

In actuality, of course, much knowledge about how to optimally carry out the task resides with the agent, and may be too costly to transfer to corporate headquarters (or other managerial layers), because of problems of eliciting the correct information or simply because the relevant is of a highly "impacted," tacit or complex, kind. Agents then have "real authority," in the sense of Aghion and Tirole (1997). In this situation, delegation colocates decision rights with this knowledge. The attendant moral hazard problem may be reduced by using more output-based contracts. Organizational structure and reward mechanisms arguably reflects the relevant tradeoff (Jensen and Meckling, 1992). Thus, the choice of how to remunerate agents is one that is complementary to a host of other issues of organizational design.

As Prendergast (2000) points out, this kind of reasoning may help explain why we may, in fact, expect a positive relation between uncertainty and incentives; thus, as he notes, “... uncertain environments result in the delegation of responsibilities, which in turn generates incentive pay based on output" (Prendergast, 2000: 1). Thus, in stable environments, direct order-giving and input monitoring will be employed by the principal. In more uncertain environments, the principal may still be able to monitor the agent's activities, but will have less of an idea of which activities the agent should optimally work on and how these activities should be balanced. Information about these issues may reside with the agent rather than with the principal. In this situation, principals likely respond by offering output-based performance contracts (Barzel, 1997). 
Clearly, we should expect the incidence and strength of the relation between environmental uncertainty and performance pay to be firm or industry dependent. There are a priori grounds for suspecting that it may be stronger in "high-tech," "dynamic," "turbulent," etc. firms and industries than in the more traditional ones. We offer two complementary explanations for this.

First, the use of delegation is likely to be more prevalent in the former kind of industries than in the latter (Mendelson and Pillai, 1999). There are number of reasons for this. "High-tech," "dynamic," etc. industries are more likely to require speedy decisionmaking on the part of incumbent firms. This is a force pulling in the direction of delegation. Moreover, in such industries, principals are likely to be more uncertain about how agents should optimally carry out tasks than in more traditional industries. This also fosters delegation, as explained above.

A second, complementary, reason why we would expect the incidence and strength of the uncertainty-incentives link to be stronger in "high-tech" firms and industries is that these are likely to make more use of multi-tasking than more traditional firms and industries. Notably, organizational practices such as planned job rotation and quality circles introduce multitasking environments. However, these are also the firms and industries for which uncertainty is already high, relatively more output-based pay being used in response. Multitasking aggravates this, since it adds to the difficulty of accurately measuring input performance, and makes it even more attractive to substitute output-based pay for direct monitoring and other ways of restricting the agent. This contradicts the Holmstrom and Milgrom hypothesis that increasing risk under multitasking lead to restriction of the number of activities that an agent is allowed to work on: Given that output-based pay is preferred under these circumstances, there is little reason to implement such restrictions. On the contrary, "dynamic" firms often stimulate multitasking for reasons of knowledge-integration and sharing.

\section{Hypotheses}

A number of hypotheses may be derived from the above discussion. The first one is simply that as a general matter, the uncertainty/incentive relation is a positive one. This relation is not directly asserted by Prendergast, who merely lists the relevant empirical evidence and tries to rationalize based on that. However, the evidence he mentions is derived from rather 
different kinds of occupations (and underlying industries) which makes it relevant to consider whether the relation may in fact be a general one. Thus, we suggest that

Hypothesis 1: There is an overall positive and significant relation between environmental uncertainty and the use of performance pay.

Still, we would expect the strength of the correlation to vary between firms belonging to different industries, for the reasons given above.

Hypothesis 2: The strength of the correlation between environmental uncertainty and the use of performance pay is sector dependent, so that firms in more "dynamic" sectors are more likely to use performance pay than those in less "dynamic" sectors, given a certain level of uncertainty.

The underlying "mechanism" driving the positive relation between uncertainty and incentives is, as his been argued, delegation. Thus, based on the above, we would expect the following hypothesis to hold true.

Hypothesis 3: Delegation and environmental uncertainty are positively correlated.

Finally, we submit that contrary to the predictions from multitasking agency theory, firms in "dynamic," high-uncertainty industries far from refraining from the use of multitasking, such firms will actually use multitasking more frequently:

Hypothesis 4: Firms that are placed in environments characterized by high uncertainty will restrict the activities that their employees can engage in less than those that are placed in low uncertainty environments.

We examine these hypotheses empirically in the remainder of the paper. $^{2}$

\footnotetext{
${ }^{2}$ Our hypotheses relate to issues of complementarity among organizational elements, since we argue that highpowered performance incentives are complementary to delegation. Athey and Stern (1998) discuss the challenges of empirically identifying complementarities in organization form. They note how difficult it is to argue that practice A is complementary with characteristic B even if A and B usually appear jointly in organizations, but offer methodologies that may handle this problem. Admittedly, in this paper we do not try
} 


\section{Empirical analysis}

\section{Measures}

While the use of pay-for-performance, delegation of responsibility and multitasking can be approximated relatively well by the use of questionnaires (see for instance, Mendelson and Pillai, 1999; Capelli and Neumark, 2001; Laursen and Foss, forthcoming), or, by observing contracts, the measurement of uncertainty is a more difficult endeavor. ${ }^{3}$ In the empirical agency literature various measures has been used to gauge the level of uncertainty facing the relevant agent. In the sub-section on "Empirical Work" in Section II of this paper, we briefly mentioned the four types of occupation, considered in the empirical agency literature (executives, sharecroppers, franchisees, and salesforce workers). In some of this literature, the measure of environmental uncertainty is idiosyncratic/specific to the activity in question. Such an idiosyncratic measure has been used in the case of - for instance - the analysis of franchising decisions, where the average proportion of discontinued outlets in the franchising sector in which the franchisor operates, has been adopted (Lafontaine, 1992). Another example of a specific measure is the number of calls it takes to close a sale, averaged across the salespeople at the responding firm (Coughlan and Narasimhan, 1992). ${ }^{4}$ For the analysis of sharecroppers, the coefficient of variation of yield has been used (Allan and Lueck, 1992). In addition to the specific measures of uncertainty, variation over time of aggregate sales data has been applied in some studies (Norton, 1987; Martin, 1988) as well survey-based data, assessing the stability in sales and forecasting accuracy (John and Weitz, 1989). In the literature on executive pay, the most commonly used proxy for risk or uncertainty is variation in returns (see for instance, Lambert and Larker, 1987; Sloan, 1992; Bushman, Indjejikian and Smith, 1996). It should be pointed out, however, that since managers are to some extent capable of controlling variations in sales, stock returns or

to tackle this issue in any direct way. However, indirectly we address the issue by noting that the two key complementary variables, that is, pay for performance and delegation, both vary with measures of uncertainty.

${ }^{3}$ However, note that our measure of performance pay only concerns the percentage of employees that are given performance pay. Thus, how high-powered incentives are from the perspective of the individual employees is, strictly speaking, not captured by this measure.

${ }^{4}$ The argument is that the longer it takes to close a sale the more important is sales efforts and the less important is environmental uncertainty (Coughlan and Narasimhan, 1992: 106). 
profitability, not all of the variance will reflect uncertainty (Lafontaine, 1992; Bushman, Indjejikian and Smith, 1996).

We here consider three measures of uncertainty, namely, (i) the extent to which firms are innovative, (ii) the perceived increase in the level of competition, (iii) within industry variance in profitability. We include different measures reflecting uncertainty, since all such measures are imperfect. With respect to innovative activity as a measure of uncertainty, it is known that innovation involves the lack of knowledge about the precise cost and outcomes of different alternatives in addition to lack of knowledge of what the alternatives are (Nelson and Winter, 1982; Freeman and Soete, 1997). However, it may be argued that innovation is an uncertain activity in the rare event of major "break-troughs", while more pedestrian incremental innovation in terms of smaller improvements are in fact routinized and hence reasonably predictable. Yet, empirical evidence has shown (Mansfield et al., 1977) that even when the fundamental knowledge base and the expected directions of advance are fairly well known, it is still often the case that firms must first engage in exploratory research, development and design before the outcome will be known, what some manageable result will cost, or even, whether useful results will emerge. As Giovanni Dosi (1988: 1134) argues “... even in the case of "normal” technical search (as opposed too the "extraordinary" exploration associated with the quest for new paradigms) strong uncertainty is present." Since innovation is not important to all firms, and since it only partially reflects environmental uncertainty, we include the two other measures. With regard to the (increased) level of competition, the idea is that if the level of competition increases, then the selection environment of the firm becomes tougher and the room for managerial slack becomes smaller. Hence, if the level of competition increases, the firm will become more dependent on the (uncertain) actions of the competitors. The final measure is the more conventional measure of uncertainty used in the existing literature, namely within-industry variance in profitability.

\section{The Empirical Model}

Based on the discussion above the probability of introducing a certain organizational practice may be specified as follows:

$$
o=f\left(\beta_{1} z, \beta_{2} x\right) .
$$


Here, $o$ is the probability of adopting an organizational practice to a certain extent within the firm, $\beta_{1}$ and $\beta_{2}$ are parameter vectors, and $z$ is a set of (exogenous) determinants of the application of certain organizational practices, related to environmental uncertainty, while $x$ is a set of other variables explaining the adoption of a certain organizational practice across business firms. The model may be made operational in the following way:

$$
\begin{aligned}
\operatorname{Prob}\left(O_{i}=0 . . j\right)= & \chi \operatorname{SECT}_{i}+\alpha \operatorname{SIZE}_{i}+\varphi \operatorname{SUBSID}_{i}+\eta I N N O+ \\
& \psi C O M P_{i}+\omega \operatorname{PROFITVAR}_{i},
\end{aligned}
$$

where $\operatorname{Prob}\left(O_{i}=0 . . j\right)$ expresses the firms' probability of adopting a given organizational practice (such as pay-for-performance or delegation of responsibility) to a certain degree within the firm (" 0 " = no use, " $1 "=$ less than $25 \%$ of the workforce involved, " $2 "=25-50 \%$ of the workforce, and " 3 " = more than $50 \%$ of the workforce involved). We control for firm size (SIZE) and for sectoral affiliation (SECT). We include three sector categories (see the paragraph below for a description). Finally, we control for whether or not the firm is a subsidiary of a larger firm (SUBSID), since decisions on the adoption of organizational practices may — at least partly — be decided at the level of the headquarter. The three measures of uncertainty include the level of novelty of the innovations produced by the firm in question (INNO) and the firm's perceived change in the level of competition (COMP) and the within-industry variance in profitability (PROFITVAR). For the possible values of INNO and COMP variables, see Table 1 below. The calculation of PROFITVAR is based on register data from Statistics Denmark. The basis of the variable is firm profitability measured as firm profits divided by firm value added. The firms in the sample have been classified according to industry at the level of eighty-three industries by Statistics Denmark (see Appendix 2 to this paper). However, given the fact that there is a very small number of firms in some industries only, the industries have been aggregated up to a total of seventy industries, in the cases were this seemed meaningful (see appendix Table 3 for details of the aggregation). Since relatively complete data are available for the years 1992, 1993 and 1994, all firms with non-missing profit data for all of the three years are included in the analysis (in order to get a balanced panel). The number of firms with non-missing 
profit data are 1610 firms $^{5}$, and hence we have 4830 observations on which to base the variance-in-profits variable. Based on those observations, the within-industry (seventy industries) variance is calculated, resulting in the PROFITVAR variable. ${ }^{6}$ It follows from the hypotheses stated in Section II, that we expect positive signs for the "uncertainty" variables.

The sectoral classification is key to Hypothesis 2 of this paper, since we claim that firms in more "dynamic" sectors use performance pay than those in less "dynamic" sectors" for given levels of uncertainty (measured as innovation or increase in the level of competition). Details of the sectoral classification applied may be found in Appendix 2 to this paper. Firm types with the strongest internal capacity to develop new products and services are assumed to belong to "high knowledge-intensive industries" (see Laursen, 2002). Firms in such industries are producing specialized machinery and instrumentation, chemicals and pharmaceuticals and ICT (Information and Communication Technology) services - the latter including banking, accounting, consultancies, advertising etc. Industries associated with the lowest capacity to develop new products and services internally ("low knowledge-intensity industries") are assumed to be the construction industry, retailing, cleaning, and to some extent supplier dominated manufacturing industries (furniture, textiles, pulp, paper and paper products etc.). Scale-intensive manufacturing industries (bulk materials and assembly) and firms in the wholesale trade industry may be considered to be intermediate in relation to knowledge-intensity ("medium knowledge-intensity industries"). Based on this sectoral classification, we estimate the following model in order to test hypothesis 2 :

$$
\begin{aligned}
\operatorname{Prob}\left(O_{i}=0 . . j\right)= & \chi_{s} S E C T_{i}+\alpha_{s} \operatorname{SIZE}_{i}+\varphi_{s} S U B S I D_{i}+\eta_{s} I N N O+ \\
& \psi_{S} \operatorname{COMP}_{i}+\omega_{s} \text { PROFITVAR } \varepsilon_{i},
\end{aligned}
$$

where the notation is the same as in Equation (2). Footsign $S$ indicates that the parameter is allowed to vary, depending on to which sector each firm belongs.

\footnotetext{
${ }^{5}$ Note that in the calculation of the within-industry variance in profits, we use all the possible observations available in the dataset. This contrasts to the econometric estimations to be found later in this paper, where we include the firms with more than 30 employees only (993 firms).

${ }^{6}$ It can been observed from Appendix Table 3, that there are two industries still (research \& development and legal activities) in each of which there is only one firm present with non-missing profit data for all of the three years. However, in the estimations it does not matter significantly for the results whether or not these two industries are included in the analysis.
} 


\section{The Data}

The main source of data for this paper is the DISKO database. The database is based on a questionnaire that aims at tracing the relationship between technical and organizational innovation in a way that permits an analysis of new principles for work organization and their implications for the use and development of the employee's qualifications in firms in the Danish private business sector. The survey was carried out by the DISKO project at Aalborg University (DK) in 1996. The questionnaire was submitted to a national sample of 4,000 firms selected among manufacturing firms with at least 20 full-time employees and non-manufacturing firms with at least 10 full-time employees. Furthermore, all Danish firms with at least 100 employees were included in the sample, i.e. a total of 913 firms. The resulting numbers of respondents were 684 manufacturing and 1,216 non-manufacturing firms, corresponding to response rates of 52 per cent and 45 per cent, respectively.

The first descriptive analysis of the survey can be found in Gjerding and Lund (1996) and in Gjerding (1997). The database is held by Statistics Denmark, and the data on the firms in the database can be linked to regular register data that are also held by Statistics Denmark. For the purposes of the present paper, data have been obtained on the size and profitability of the firms in the sample from regular register data. The choice was made to work only with firms with more than 30 employees, since we are dealing with the application of formal work practices — practices which are simply less meaningful for smaller companies (why use delegation, if the firm is not larger than a typical work team?). By retaining only firms in the sample that are larger than 30 employees, we end up with a total of 993 firms.

Table 1 displays descriptive statistics for the variables used in this paper. Appendix 1 can be inspected for a description of the questions from the survey on the basis of which the variables have been constructed. Only about 10 per cent of the firms do not use delegation of responsibility (10.4 per cent) to varying degrees, while just about half of the firms in the sample apply pay-for-performance (52.9 per cent). Also about half of the firms report use of quality circles (47.4) and planned job rotation (44.6). Most firms (79.3 per cent) feel that the level of competition has increased over recent years. While it is clearly observed that the perceived level of competition is highly skewed, it is also evident that the perceived increased level of competition varies in degree. The sample includes 391 non-innovators, 434 firms that produced products/services that were new only to the firm itself, 89 firms that 
Table 1: Descriptive statistics for a set of DISKO variables $(\mathrm{N}=993)$

\begin{tabular}{|c|c|c|c|}
\hline & & $\begin{array}{r}\text { Number of } \\
\text { firms }\end{array}$ & $\%$ of sample \\
\hline \multirow[t]{3}{*}{ Industry affiliation } & Low-KI & 390 & 39.3 \\
\hline & Medium-KI & 366 & 36.9 \\
\hline & High-KI & 237 & 23.9 \\
\hline$\overline{\text { Number of employees }}$ & 31-100 employees & 312 & 31.4 \\
\hline \multirow[t]{2}{*}{ (SIZE) } & 101-200 employees & 203 & 20.4 \\
\hline & $200+$ employees & 478 & 48.1 \\
\hline Subsidiary & No & 409 & $\overline{41.2}$ \\
\hline (SUBSID) & Yes & 584 & 58.8 \\
\hline Competition & Strongly decreased & 1 & $\overline{0.1}$ \\
\hline \multirow[t]{4}{*}{ (COMP) } & Somewhat decreased & 10 & 1.0 \\
\hline & Unchanged & 194 & 19.5 \\
\hline & Somewhat increased & 339 & 34.1 \\
\hline & Strongly increased & 449 & 45.2 \\
\hline Product innovation & No innovation & 391 & 39.4 \\
\hline \multirow[t]{3}{*}{ (INNO) } & Innovation new to the firm & 434 & 43.7 \\
\hline & Innovation new to the country & 89 & 9.0 \\
\hline & Innovation new to the world & 79 & 8.0 \\
\hline Pay-for-performance & Not used & 525 & 52.9 \\
\hline \multirow[t]{3}{*}{ (PPAY) } & $<25 \%$ of the workforce & 194 & 19.5 \\
\hline & $25-50 \%$ of the workforce & 79 & 8.0 \\
\hline & $>50 \%$ of the workforce & 195 & 19.6 \\
\hline Delegation & Not used & 103 & 10.4 \\
\hline \multirow[t]{3}{*}{ (DR) } & $<25 \%$ of the workforce & 240 & 24.2 \\
\hline & $25-50 \%$ of the workforce & 265 & 26.7 \\
\hline & $>50 \%$ of the workforce & 385 & 38.8 \\
\hline Quality circles & Not used & 522 & 52.6 \\
\hline \multirow[t]{3}{*}{ (QC) } & $<25 \%$ of the workforce & 264 & 26.6 \\
\hline & $25-50 \%$ of the workforce & 111 & 11.2 \\
\hline & $>50 \%$ of the workforce & 96 & 9.7 \\
\hline Planned job rotation & Not used & 550 & 55.4 \\
\hline \multirow[t]{3}{*}{ (PJR) } & $<25 \%$ of the workforce & 288 & 29.0 \\
\hline & $25-50 \%$ of the workforce & 93 & 9.4 \\
\hline & $>50 \%$ of the workforce & 62 & 6.2 \\
\hline
\end{tabular}

produced products/services that were new to the national market, while 79 firms introduced products/services that were new to the world. 


\section{Estimation}

Since the dependent variable is a discrete and inherently ordered multinomial-choice variable, an ordered probit model is applied as the means of estimation (for an exposition of ordered probit models, see Greene, 1997: 926-931). Table 2 contains the estimations relevant to hypotheses 1,3 and 4, while the relevant estimations to hypothesis 2 are to be found in Table 3. The marginal effects corresponding to the coefficients found in Table 2 are reported in Appendix Tables A1-A4, while marginal effects corresponding to the coefficients reported in Table 3 are to be found in Appendix Tables A5. The null hypothesis that the slopes of the explanatory variables are zero is strongly rejected by the likelihood ratio test in all of the four models $(i-v i)$ from Table 2 , as well as for the model estimated in Table 3. Model (i), in Table 2, tests Hypothesis 1 ("There is an overall positive and significant relation between environmental uncertainty and the use of performance pay"). It can be seen from the estimation of model (i) that being a subsidiary increases the probability of adopting pay-for-performance to an increasing degree. This conclusion can be made, based on the fact that the parameter for SUBSID is positive and significant and since the marginal effect for the SUBSID variable is negative (see Appendix Table A1) only in the case of no use (PPAY=0), while the marginal effect is positive in the case of at all levels of adoption (PPAY=1, 2, 3). It can also be noted that the marginal effects are particularly large in the case of PPAY $=3$. The SIZE variable is insignificant. Of our three uncertainty measures, the parameter for increased level of competition is insignificant. In contrast, parameter for the innovation variable (INNO) is significant and the marginal effect is negative only in the case of no use of pay-for-performance. The effect is by far strongest in the case of PPAY $=3$ ( $>50 \%$ of the workforce involved). Moreover, the parameter for PROFITVAR is very significant and has the right sign, according to Hypothesis 1 . Also in this case, the marginal effect is negative only in the case of no use of pay-for-performance (PPAY $=0)$. Here, the effect is strongly negative, while the effect is strongly positive in the case of PPAY $=3$. In sum, we find rather strong support for Hypothesis 1 .

Hypothesis 2 ("The strength of the correlation between environmental uncertainty and the use of performance pay is sector dependent, so that firms in more "dynamic" sectors are more likely to use performance pay than those in less "dynamic" sectors, given a certain level of uncertainty") is put under scrutiny in Table 3, where the parameters are allowed to differ for each variable, according to whether the firms belong to low, medium, 
Table 2: Probit estimation explaining the adoption of four work practices $(\mathrm{N}=993)$

\begin{tabular}{|c|c|c|c|c|c|c|c|c|}
\hline & \multicolumn{2}{|c|}{ Model(i) } & \multicolumn{2}{|c|}{ Model (ii) } & \multicolumn{2}{|c|}{ Model (iii) } & \multicolumn{2}{|c|}{ Model (iv) } \\
\hline \multirow{3}{*}{$\begin{array}{l}\text { Dependent variable } \\
\text { Independent variables }\end{array}$} & \multicolumn{2}{|c|}{ PPAY } & \multicolumn{2}{|c|}{ DR } & \multirow{2}{*}{\multicolumn{2}{|c|}{$\begin{array}{c}\text { QC } \\
\text { (Quality circles) }\end{array}$}} & \multirow{2}{*}{\multicolumn{2}{|c|}{$\begin{array}{c}\text { PJR } \\
\text { (Planned job rotation) }\end{array}$}} \\
\hline & (Pay-for-per & rmance) & (Delegation of $r$ & sibility) & & & & \\
\hline & Estimate & $p$-value & Estimate & $p$-value & Estimate & $p$-value & Estimate & $p$-value \\
\hline LOW KI & -0.478 & 0.004 & 0.640 & 0.000 & -0.568 & 0.000 & -0.775 & 0.000 \\
\hline MEDIUM KI & -0.407 & 0.014 & 0.837 & 0.000 & -0.527 & 0.002 & -0.627 & 0.000 \\
\hline HIGH KI & -0.493 & 0.005 & 0.906 & 0.000 & -0.290 & 0.100 & -0.715 & 0.000 \\
\hline SIZE & 0.011 & 0.140 & 0.010 & 0.137 & 0.011 & 0.110 & 0.019 & 0.005 \\
\hline SUBSID & 0.209 & 0.006 & 0.122 & 0.096 & 0.278 & 0.000 & 0.138 & 0.075 \\
\hline INNO & 0.163 & 0.000 & 0.067 & 0.103 & 0.098 & 0.023 & 0.153 & 0.000 \\
\hline COMP & -0.008 & 0.861 & 0.093 & 0.033 & 0.031 & 0.501 & 0.083 & 0.076 \\
\hline PROFITVAR & 3.051 & 0.000 & 1.536 & 0.287 & 1.316 & 0.204 & 1.187 & 0.300 \\
\hline Log likelihood & -1148.7 & & -1271.7 & & -1131.5 & & -1051.4 & \\
\hline Restricted log likelihood & -1168.8 & & -1289.1 & & -1152.9 & & -1073.6 & \\
\hline Likelihood ratio test & 40.1 & & 34.6 & & 42.9 & & 44.6 & \\
\hline
\end{tabular}


or high knowledge intensive sectors. SIZE is again insignificant — and even more so as compared to the case, where a single parameter was assumed. Being a subsidiary of a larger firm increases the probability of adopting pay-for performance for what concerns low and high knowledge intensive sectors, whereas the parameter is insignificant with respect to medium knowledge intensive firms. The marginal effects are particularly strong for PPAY $=$ 3 ( $>50 \%$ of the workforce involved), both for low and high knowledge intensive sectors (see Appendix Table A5). Again — as when a common parameter was assumed - COMP is insignificant. However, the second uncertainty variable, INNO is positive, significant and the marginal effects are negative only in the case of no use of PPAY, for all of the three sectors. Nevertheless, the size of the parameter for the high knowledge intensive sector is about twice the size of the parameters for the two other sectors, and marginal effects are also much stronger for the high knowledge intensive sector — in particular for PPAY $=3$ (see Appendix Table A5). In other words, if firms produce innovations to an increasing degree of novelty, they are much more likely to adopt pay-for-performance involving the majority of the workforce and this relationship is the strongest for firms affiliated to high knowledgeintensity sectors. When it comes to the profit-variance measure (PROFITVAR), we find that the results are strongly consistent with hypothesis 2 of this paper, since the parameter is significant in the case of medium and high knowledge intensive firms. Moreover the parameter is larger for high knowledge intensive firms than for medium knowledge intensive firms. For both of the two significant types of firms interpretation of the parameters is straight-forward, since the marginal effects are negative only in the case of no use of PPAY. Overall, the findings give strong support to Hypothesis 2.

Model (ii) in Table 2 examines Hypothesis 3 ("Delegation and environmental uncertainty are positively correlated"). In this case, SUBSID is significant, but the relevant marginal effects (see Appendix, Table A2) are only positive in the case of DR $=3$. That is, firms affiliated to a larger firm are only more prone do adopt delegation of responsibility when more than 50 per cent of the employees are involved. In fact, the marginal effect is high and negative if less than 25 per cent of the workforce is involved. The parameter for INNO just escapes the ten per cent level of significance, and again, the marginal effect is only positive for what concerns PPAY $=3$ ( $>50 \%$ of the workforce involved). Another measure reflecting levels of uncertainty, COMP is significant at the five per cent level, but once more the marginal effect is positive only for what concerns PPAY $=3$. In other words, 
Table 3: Probit estimation explaining the adoption of pay-for-performance, sectoral estimation $(\mathrm{N}=993)$

\begin{tabular}{llrr}
\hline \hline & & Estimate & $p$-value \\
\hline INTERCEPT & Low-KI & -0.584 & 0.017 \\
& Medium-KI & -0.068 & 0.811 \\
& High-KI & -1.296 & 0.000 \\
\hline SIZE & Low-KI & -0.009 & 0.749 \\
& Medium-KI & 0.008 & 0.397 \\
& High-KI & 0.022 & 0.427 \\
\hline SUBSID & Low-KI & 0.318 & 0.011 \\
& Medium-KI & 0.081 & 0.530 \\
& High-KI & 0.279 & 0.076 \\
\hline INNO & Low-KI & 0.140 & 0.073 \\
& Medium-KI & 0.125 & 0.065 \\
& High-KI & 0.260 & 0.003 \\
\hline COMP & Low-KI & 0.045 & 0.540 \\
& Medium-KI & -0.117 & 0.141 \\
& High-KI & 0.099 & 0.324 \\
\hline PROFITVAR & Low-KI & 1.014 & 0.415 \\
& Medium-KI & 6.754 & 0.019 \\
\hline Log likelihood & High-KI & 9.153 & 0.006 \\
\hline
\end{tabular}

firms facing tougher competition are more likely to adopt delegation of responsibility only when more than 50 per cent of the employees are involved in the delegation. The parameter for PROFITVAR has the expected sign, but is not significant. To conclude on Hypothesis 2, it can be said that the hypothesis finds support to the extent that if firms face more competitive environments, then they are more likely to use delegation of responsibility, conditional on whether delegation involves the majority of the workforce.

With respect to hypothesis 4 ("Firms that are placed in environments characterized by high uncertainty will restrict the activities that their employees can engage in less than those that are placed in low uncertainty environments"), we apply two measures of "multitasking." The first has to do with the use of "quality circles" (QC), while the second has to do with the application of "planned job rotation". In both cases we argue that those 
work practices allows for more multitasking, and hence restrict the employees less. The relevant estimations can be found in models (iii) and (vi) in Table 2. In these two models, the marginal effects for all variables (except for the three intercepts) are negative (see Appendix Table A3-A4) only in the case of no use (QC, PJR =0), while the marginal effects are positive in the case of at all levels of adoption (QC, PJR $=1,2,3)$. SIZE is insignificant in the case of QC, while it is positive and significant for what concerns PJR. Hence, in the latter situation, larger firms seem more likely to adopt planned job rotation. SUBSID is positive and significant in both models, meaning that firms belonging to a larger firm are more likely to use quality circles, as well as planned job rotation. INNO is positive and significant in both models as well, implying that firms with the ability to produce (uncertain) innovations are more prone to adopt QC and PJR. The other proxy for uncertainty, COMP, is significant at the ten per cent level in affecting the likelihood of adopting planned job rotation, while it is insignificant when confronting quality circles. In other words, firms which perceive a tougher competition regime are more likely to adopt quality planned job rotation. In sum, the evidence is somewhat supportive of hypothesis 4 .

\section{Concluding Discussion}

This paper began by observing the seemingly tenuous tradeoff between risk and uncertainty. We then went on to suggest - in line with other authors - that this may be caused by the widespread use of delegation of decision rights. Moreover, we argued firms should restrict their employees less, when faced with a more uncertain environment. This prediction is in contrast to the prediction of the standard agency theory. Subsequently, we made an attempt to shed light on these matters empirically, as empirical research on these matters may be characterized as relatively scant. It was further argued that firms' ability to produce innovations of an increasing degree of novelty, and firms' perceived change in competition regime, as well as with-in industry variations in profitability may serve as (imperfect) measures of environmental uncertainty.

The evidence was found to be consistent with the hypothesis stating that there is an overall positive and significant relation between environmental uncertainty and the use of performance pay in the sense that the likelihood of adopting pay-for-performance increases with firms' ability to produce product innovations, in particular when the majority of the 
workforce is involved in the pay-for-performance schemes. However, not only did we conjecture that there an overall positive and significant relation between environmental uncertainty and the use of pay-for-performance, we also added the prediction that the strength of the correlation between environmental uncertainty and the use of performance pay is sector dependent, so that firms in more "dynamic" sectors are more likely to use performance pay than those in less "dynamic" sectors, given a certain level of uncertainty. It was concluded that if firms produce innovations to an increasing degree of novelty, they are much more likely to adopt pay-for-performance involving the majority of the workforce and that this relationship was found to be the strongest for firms affiliated to high knowledgeintensity sectors. Moreover, we found that the relationship between the level of adoption of pay-for-performance schemes and uncertainty - measured as within-industry variance in profits - becomes increasingly strong, when the level of knowledge intensity increases.

With respect to the hypothesis claiming that delegation and environmental uncertainty are positively correlated, we found support for this claim to the extent that if firms face more uncertain environments, then they are more likely to use delegation of responsibility, conditional on the observation that delegation involves the majority of the workforce. Although the parameter for the measure of within-industry variance in profitability turned out not to be significant (albeit positive) in explaining the use of delegation in firms, the opposite prediction from standard agency theory (a negative relation) found no support in the available evidence.

We also examined the multitasking agency hypothesis (the Holmström-Milgrom hypothesis) which states that, as risk increases, the flexibility of agents is restricted. We found no evidence of such a relationship. First, we found that the parameter for withinindustry variance in profitability was positive (although not significant). Second, we found some evidence consistent with the view that firms which are placed in environments characterized by high uncertainty will restrict the activities that their employees can engage in less than those that are placed in low uncertainty environments. In this context, we found that firms with the ability to produce (uncertain) innovations are more prone to adopt quality circles and planned job rotation. Moreover, we found the final proxy for uncertainty, an increased level of competition, to affect positively the likelihood of adopting planned job rotation. Multitasking adds to the difficulty of accurately measuring input performance, and makes it more attractive to substitute output-based pay for direct monitoring and other ways 
of restricting the agent. Given that output-based pay is preferred under these circumstances, there is little reason to implement such restrictions. On the contrary, we conjecture that "dynamic" firms often stimulate multitasking for reasons of knowledge-integration and sharing.

\section{Appendices}

\section{Appendix 1: The questions from the DISKO survey that are used in this paper}

1. How large a share of the firm's workforce is involved in following ways of organising work? (none, $<25 \%, 25 \%-50 \%,>50 \%$, corresponding to a 4 point Lickert scale)
a. Delegation of responsibility [DR]
b Performance pay (not piece work) [PPAY]
c. Quality circles $[\mathrm{QC}]$
d. Planned job rotation [PLJ]

2. Has the firm introduced new products/services during the period 1993-95 when excepting minor improvements of existing products? (yes/no)

If the respondent answered yes to this question he/she was asked whether similar products/services could be found...
a. ...on the Danish market (yes/no)
b. ...on the world market (yes/no)

If the respondent answered that a similar product could be found both on the Danish market and on the world market, the innovation variable was coded with the value of 1 ("new to the firm"). If respondent answered that a similar product could be found on the world market, but not on the Danish market, the innovation variable was coded with the value of 2 ("new to the country"). If the respondent answered that similar product could neither be found on the Danish market, nor on the world market, the innovation variable was coded with the value of 3 ("new to the world"). If the respondent answered no the first question under (4), the variable was assigned with the value of 0 (non-innovator).

3. To which extent has competition from other firms changed during recent years?
a. Strongly decreased
b. Somewhat decreased
c. Unchanged
d. Somewhat increased
e. Strongly increased

If the respondent answered "strongly decreased", the variable was coded with the value of zero, while the variable was coded with the value of four, in the case where respondent answered "strongly increased". 


\section{Appendix 2: The Assignment of Industries/Firms Into Three Sectoral Categories}

\begin{tabular}{|c|c|c|c|c|c|}
\hline No. & Industry & Sector & No. & Industry & Sector \\
\hline 1 & Production etc. of meat and meat products & Med-KI & 43 & Sale of motor vehicles, motorcycles etc. & Low-KI \\
\hline 2 & Manufacture of dairy products & Med-KI & 44 & Maintenance and repair of motor vehicles & Low-KI \\
\hline 3 & Manufacture of other food products & Med-KI & 45 & Service stations & Low-KI \\
\hline 4 & Manufacture of beverages & Med-KI & 46 & Ws. of agricul. raw materials, live animals & Med-KI \\
\hline 5 & Manufacture of tobacco products & Med-KI & 47 & Ws. of food, beverages and tobacco & Med-KI \\
\hline 6 & Manufacture of textiles and textile products & Low-KI & 48 & Ws. of household goods & Med-KI \\
\hline 7 & Mfr. of wearing apparel; dressing etc. of fur & Low-KI & 49 & Ws. of wood and construction materials & Med-KI \\
\hline 8 & Mfr. of leather and leather products & Low-KI & 50 & Ws. of other raw mat. and semimanufactures & Med-KI \\
\hline 9 & Mfr. of wood and wood products & Low-KI & 51 & Ws. of machinery, equipment and supplies & Med-KI \\
\hline 10 & Mfr. of pulp, paper and paper products & Low-KI & 52 & Commission trade and other wholesale trade & Med-KI \\
\hline 11 & Publishing of newspapers & Low-KI & 53 & Re. sale of food in non-specialised stores & Low-KI \\
\hline 12 & Publishing activities, excl. newspapers & Low-KI & 54 & Re. sale of food in specialised stores & Low-KI \\
\hline 13 & Printing activities etc. & Low-KI & 55 & Department stores & Low-KI \\
\hline 14 & Mfr. of refined petroleum products etc. & Med-KI & 56 & Retail sale of phar. Goods, cosmetic art. etc. & Low-KI \\
\hline 15 & Mfr. of chemical raw materials & High-KI & 57 & Re. sale of clothing, footwear etc. & Low-KI \\
\hline 16 & Mfr. of paints, soap, cosmetics, etc. & Med-KI & 58 & Re. sale of furniture, household appliances & Low-KI \\
\hline 17 & Mfr. of pharmaceuticals etc. & High-KI & 59 & Re. sale in other specialised stores & Low-KI \\
\hline 18 & Mfr. of plastics and synthetic rubber & Med-KI & 60 & Repair of personal and household goods & Low-KI \\
\hline 19 & Mfr. of glass and ceramic goods etc. & Low-KI & 61 & Hotels etc. & Low-KI \\
\hline 20 & Mfr. of cement, bricks, concrete ind. etc. & Med-KI & 62 & Restaurants etc. & Low-KI \\
\hline 21 & Mfr. of basic metals & Med-KI & 63 & Transport via railways and buses & Low-KI \\
\hline 22 & Mfr. construction materials of metal etc. & Med-KI & 64 & Taxi operation and coach services & Low-KI \\
\hline 23 & Mfr. of hand tools, metal packaging etc. & Low-KI & 65 & Freight transport by road and via pipelines & Low-KI \\
\hline 24 & Mfr. of marine engines, compressors etc. & High-KI & 66 & Water transport & Low-KI \\
\hline 25 & Mfr. of other general purpose machinery & High-KI & 67 & Air transport & Low-KI \\
\hline 26 & Mfr. of agricultural and forestry machinery & High-KI & 68 & Cargo handling, harbours etc.; travel agencies & Low-KI \\
\hline 27 & Mfr. of machinery for industries etc. & High-KI & 69 & Monetary intermediation & High-KI \\
\hline 28 & Mfr. of domestic appliances n.e.c. & Med-KI & 70 & Other financial intermediation & High-KI \\
\hline 29 & Mfr. of office machinery and computers & High-KI & 71 & Insurance and pension funding & High-KI \\
\hline 30 & Mfr. of radio and communication equipment etc. & High-KI & 72 & Activities auxiliary to financial intermediates & High-KI \\
\hline 31 & Mfr. of medical and optical instruments etc. & High-KI & 73 & Letting of own property & Low-KI \\
\hline 32 & Building and repairing of ships and boats & Med-KI & 74 & Real estate agents etc. & Lo \\
\hline 33 & Mfr. of transport equipment excl. ships, etc. & Med-KI & 75 & Renting of machinery and equipment etc. & \\
\hline 34 & Mfr. of furniture & Low-KI & 76 & Computer and related activity & High-KI \\
\hline 35 & Mfr. of toys, gold and silver articles etc. & Low-KI & 77 & Research and development & High-KI \\
\hline 36 & General contractors & Low-KI & 78 & Legal activities & High-KI \\
\hline 37 & Bricklaying & Low-KI & 79 & Accounting, book-keeping and auditing activities & High-KI \\
\hline 38 & Install. of electrical wiring and fittings & Low-KI & 80 & Consulting engineers, architects etc. & High-KI \\
\hline 39 & Plumbing & Low-KI & 81 & Advertising & High-KI \\
\hline 40 & Joinery installation & Low-KI & 82 & Building-cleaning activities & Low-KI \\
\hline 41 & Painting and glazing & Low-KI & 83 & Other business services & High-KI \\
\hline 42 & Other construction works & Low-KI & & & \\
\hline
\end{tabular}

Note: Low-KI = low knowledge-intensity sectors; Med-KI = medium knowledge-intensity sectors; High-KI = high knowledge-intensity sectors. 


\section{Appendix 3: The Assignment of Industries/Firms Into Profit Variance Categories}

\begin{tabular}{|c|c|c|c|c|c|c|}
\hline No. Industry & $\mathrm{N}$ & Variance & No. & Industry & $\mathrm{N}$ & Variance \\
\hline V1 Production etc. of meat and meat products (i1) & 30 & 0.024 & V36 & Painting and glazing (i41) & 66 & 0.018 \\
\hline V2 Manufacture of dairy products (i2) & 27 & 0.047 & V37 & Other construction works (i42) & 33 & 0.010 \\
\hline $\begin{array}{l}\text { V3 Manufacture of other food products (i3) } \\
\text { Manufacture of tobacco products (i5) }\end{array}$ & 129 & 0.043 & V38 & Sale of motor vehicles, motorcycles etc. (i43) & 243 & 0.061 \\
\hline V4 Manufacture of beverages (i4) & 15 & 0.011 & V39 & $\begin{array}{l}\text { Maintenance and repair of motor vehicles (i44) } \\
\text { Service stations (i45) }\end{array}$ & 51 & 0.008 \\
\hline V5 Manufacture of textiles and textile products (i6) & 69 & 0.042 & V40 & Ws. of agricul. raw materials, live animals (i46) & 48 & 0.026 \\
\hline $\begin{array}{l}\text { V6 Mfr. of wearing apparel; dressing etc. of fur (i7) } \\
\text { Mfr. of leather and leather products (i8) }\end{array}$ & 48 & 0.070 & V41 & Ws. of food, beverages and tobacco (i47) & 96 & 0.065 \\
\hline V7 Mfr. of wood and wood products (i9) & 75 & 0.022 & V42 & Ws. of household goods (i48) & 150 & 0.037 \\
\hline V8 Mfr. of pulp, paper and paper products (i10) & 66 & 0.085 & V43 & Ws. of wood and construction materials (i49) & 51 & 0.051 \\
\hline $\begin{array}{l}\text { Publishing of newspapers (i11) } \\
\text { Publishing activities, excl. newspapers (i12) }\end{array}$ & 42 & 0.006 & V44 & Ws. of other raw mat. and semimanufactures (i50) & 87 & 0.034 \\
\hline V10 Printing activities etc. (i13) & 75 & 0.065 & V45 & Ws. of machinery, equipment and supplies (i51) & 336 & 0.049 \\
\hline $\begin{array}{l}\text { Mfr. of refined petroleum products etc. (i14) } \\
\text { Mfr. of chemical raw materials (i15) }\end{array}$ & 24 & 0.030 & V46 & Commission trade and other wholesale trade (i52) & 24 & 0.015 \\
\hline V12 Mfr. of paints, soap, cosmetics, etc. (i16) & 63 & 0.036 & V47 & $\begin{array}{l}\text { Re. sale of food in non-specialised stores (i53) } \\
\text { Department stores (i55) }\end{array}$ & 63 & 0.032 \\
\hline V13 Mfr. of pharmaceuticals etc. (i17) & 27 & 0.035 & V48 & Re. sale of food in specialised stores (i54) & 15 & 0.004 \\
\hline V14 Mfr. of plastics and synthetic rubber (i18) & 135 & 0.023 & V49 & Retail sale of phar. goods, cosmetic art. etc. (i56) & 120 & 0.007 \\
\hline $\begin{array}{l}\text { V15 Mfr. of glass and ceramic goods etc. (i19) } \\
\text { Mfr. of cement, bricks, concrete ind. etc. (i20) }\end{array}$ & 81 & 0.024 & V50 & Re. sale of clothing, footwear etc. (i57) & 78 & 0.029 \\
\hline V16 Mfr. of basic metals (i21) & 69 & 0.045 & V51 & $\begin{array}{l}\text { Re. sale of furniture, household appliances (i58) } \\
\text { Repair of personal and household goods (i60) }\end{array}$ & 90 & 0.019 \\
\hline V17 Mfr. construction materials of metal etc. (i22) & 84 & 0.018 & V52 & Re. sale in other specialised stores (i59) & 51 & 0.018 \\
\hline V18 Mfr. of hand tools, metal packaging etc. (i23) & 102 & 0.030 & V53 & Hotels etc. (i61) & 63 & 0.086 \\
\hline V19 Mfr. of marine engines, compressors etc. (i) 24 & 54 & 0.033 & V54 & Restaurants etc. (i62) & 39 & 0.010 \\
\hline V20 Mfr. of other general purpose machinery (i)25 & 105 & 0.057 & V55 & Transport via railways and buses (i63) & 18 & 0.015 \\
\hline V21 Mfr. of agricultural and forestry machinery (i26) & 27 & 0.082 & V56 & Taxi operation and coach services (i64) & 30 & 0.003 \\
\hline V22 Mfr. of machinery for industries etc. (i27) & 108 & 0.019 & V57 & Freight transport by road and via pipelines (i65) & 165 & 0.008 \\
\hline V23 Mfr. of domestic appliances n.e.c. (i28) & 30 & 0.036 & V58 & $\begin{array}{l}\text { Water transport (i66) } \\
\text { Air transport (i67) }\end{array}$ & 15 & 0.107 \\
\hline V24 Mfr. of office machinery and computers (i29) & 84 & 0.068 & V59 & Cargo handling, harbours etc.; travel agencies (i68) & 96 & 0.028 \\
\hline V25 Mfr. of radio and communication equipment etc. & 51 & 0.060 & V60 & $\begin{array}{l}\text { Monetary intermediation (i69) } \\
\text { Other financial intermediation (i70) } \\
\text { Insurance and pension funding (i71) } \\
\text { Activities auxiliary to financial intermediates (i72) }\end{array}$ & 15 & 0.089 \\
\hline V26 Mfr. of medical and optical instruments etc. (i31) & 90 & 0.045 & V61 & $\begin{array}{l}\text { Letting of own property (i73) } \\
\text { Real estate agents etc. (i74) }\end{array}$ & 18 & 0.012 \\
\hline V27 Building and repairing of ships and boats (i32) & 24 & 0.101 & V62 & Renting of machinery and equipment etc. (i75) & 18 & 0.633 \\
\hline V28 Mfr. of transport equipment excl. ships, etc. (i33) & 60 & 0.091 & V63 & Computer and related activity (i76) & 69 & 0.023 \\
\hline V29 Mfr. of furniture (i34) & 156 & 0.022 & V64 & Research and development (i77) & 3 & 0.025 \\
\hline V30 Mfr. of toys, gold and silver articles etc. (i35) & 36 & 0.017 & V65 & Legal activities (i78) & 3 & 0.000 \\
\hline V31 General contractors (i36) & 177 & 0.030 & V66 & $\begin{array}{l}\text { Accounting, book-keeping and auditing activities } \\
\text { (i79) }\end{array}$ & 33 & 0.003 \\
\hline V32 Bricklaying (i37) & 36 & 0.019 & V67 & Consulting engineers, architects etc. (i80) & 90 & 0.019 \\
\hline V33 Install. of electrical wiring and fittings (i38) & 114 & 0.014 & V68 & Advertising (i81) & 18 & 0.006 \\
\hline V34 Plumbing (i39) & 66 & 0.008 & V69 & Building-cleaning activities (i82) & 45 & 0.007 \\
\hline V35 Joinery installation (i40) & 84 & 0.015 & V70 & Other business services (i83) & 27 & 0.079 \\
\hline
\end{tabular}

Note: The numbers in brackets (i1..i70) refers to the industry number in Appendix Table 2. 
Appendix Table A1: Marginal effects from probit, adoption pay-for-performance of across 993 Danish firms

\begin{tabular}{lrrrr}
\hline \hline & PPAY $=0$ & PPAY $=1$ & PPAY $=2$ & PPAY $=3$ \\
\hline LOW_KI & 0.190 & -0.032 & -0.028 & -0.130 \\
MEDIUM_KI & 0.162 & -0.027 & -0.024 & -0.110 \\
HIGH_KI & 0.196 & -0.033 & -0.029 & -0.134 \\
SIZE & -0.004 & 0.001 & 0.001 & 0.003 \\
SUBSID & -0.083 & 0.014 & 0.012 & 0.057 \\
INNO & -0.065 & 0.011 & 0.010 & 0.044 \\
COMP & 0.003 & -0.001 & -0.001 & -0.002 \\
PROFITVAR & -1.214 & 0.205 & 0.181 & 0.828 \\
\hline \hline
\end{tabular}

Appendix Table A2: Marginal effects from probit, adoption of delegation of responsability across 993 Danish firms

\begin{tabular}{lrrrr}
\hline \hline & DR=0 & DR=1 & DR=2 & DR=3 \\
\hline LOW_KI & -0.111 & -0.124 & -0.009 & 0.245 \\
MEDIUM_KI & -0.146 & -0.162 & -0.012 & 0.320 \\
HIGH_KI & -0.158 & -0.175 & -0.013 & 0.346 \\
SIZE & -0.002 & -0.002 & 0.000 & 0.004 \\
SUBSID & -0.021 & -0.024 & -0.002 & 0.047 \\
INNO & -0.012 & -0.013 & -0.001 & 0.026 \\
COMP & -0.016 & -0.018 & -0.001 & 0.036 \\
PROFITVAR & -0.267 & -0.297 & -0.023 & 0.587 \\
\hline \hline
\end{tabular}

Appendix Table A3: Marginal effects from probit, adoption quality circles of across 993

Danish firms

\begin{tabular}{lrrrr}
\hline \hline & $\mathrm{QC}=0$ & $\mathrm{QC}=1$ & $\mathrm{QC}=2$ & $\mathrm{QC}=3$ \\
\hline LOW_KI & 0.226 & -0.066 & -0.068 & -0.092 \\
MEDIUM_KI & 0.210 & -0.061 & -0.063 & -0.086 \\
HIGH_KI & 0.115 & -0.034 & -0.035 & -0.047 \\
SIZE & -0.004 & 0.001 & 0.001 & 0.002 \\
SUBSID & -0.111 & 0.032 & 0.033 & 0.045 \\
INNO & -0.039 & 0.011 & 0.012 & 0.016 \\
COMP & -0.012 & 0.004 & 0.004 & 0.005 \\
PROFITVAR & -0.524 & 0.153 & 0.156 & 0.214 \\
\hline \hline
\end{tabular}


Appendix Table A4: Marginal effects from probit, adoption of planned job rotation across 993 Danish firms

\begin{tabular}{lrrrr}
\hline \hline & PJR=0 & PLJ=1 & PLJ=2 & PLJ=3 \\
\hline LOW_KI & 0.306 & -0.126 & -0.091 & -0.089 \\
MEDIUM_KI & 0.248 & -0.102 & -0.073 & -0.072 \\
HIGH_KI & 0.283 & -0.117 & -0.084 & -0.082 \\
SIZE & -0.007 & 0.003 & 0.002 & 0.002 \\
SUBSID & -0.055 & 0.023 & 0.016 & 0.016 \\
INNO & -0.060 & 0.025 & 0.018 & 0.018 \\
COMP & -0.033 & 0.014 & 0.010 & 0.010 \\
PROFITVAR & -0.469 & 0.194 & 0.139 & 0.137 \\
\hline \hline
\end{tabular}

Appendix Table A5: Marginal effects from probit estimation with sector-specific slopes, adoption of pay-for-performance across 993 Danish firms

\begin{tabular}{llrrrr}
\hline \hline & & PPAY=0 & PPAY=1 & PPAY=2 & PPAY=3 \\
\hline INTERCEPT & Low-KI & 0.233 & -0.040 & -0.035 & -0.157 \\
& Medium-KI & 0.027 & -0.005 & -0.004 & -0.018 \\
& High-KI & 0.516 & -0.088 & -0.078 & -0.349 \\
\hline SIZE & Low-KI & 0.003 & -0.001 & -0.001 & -0.002 \\
& Medium-KI & -0.003 & 0.001 & 0.001 & 0.002 \\
& High-KI & -0.009 & 0.002 & 0.001 & 0.006 \\
\hline SUBSID & Low-KI & -0.127 & 0.022 & 0.019 & 0.086 \\
& Medium-KI & -0.032 & 0.006 & 0.005 & 0.022 \\
& High-KI & -0.111 & 0.019 & 0.017 & 0.075 \\
\hline INNO & Low-KI & -0.056 & 0.010 & 0.009 & 0.038 \\
& Medium-KI & -0.050 & 0.009 & 0.008 & 0.034 \\
& High-KI & -0.104 & 0.018 & 0.016 & 0.070 \\
\hline COMP & Low-KI & -0.018 & 0.003 & 0.003 & 0.012 \\
& Medium-KI & 0.047 & -0.008 & -0.007 & -0.032 \\
& High-KI & -0.040 & 0.007 & 0.006 & 0.027 \\
\hline PROFITVAR & Low-KI & -0.403 & 0.069 & 0.061 & 0.273 \\
& Medium-KI & -2.687 & 0.461 & 0.407 & 1.820 \\
& High-KI & -3.641 & 0.624 & 0.551 & 2.466 \\
\hline \hline
\end{tabular}




\section{References}

Aghion, P. and J. Tirole, 1997, Formal and Real Authority in Organization, Journal of Political Economy 1-29.

Allan, D. and D. Lueck, 1992, Contract Choice in Modern Agriculture: Crop-Share versus Cash Rent, Journal of Law and Economics 35, 397-426.

Anderson, E., 1985, The Salesperson as an Outside Agent or Employee: A Transaction Cost Analysis, Management Science 4, 234-254.

Anderson, E. and D. Scmittlein, 1984, Integration of the Salesforce: An Empirical Examination, Rand Journal of Economics 15, 385-395.

Athey, S. and S. Stern, 1998, An Empirical Framework for Testing Theories About Complementarity in Organizational Design, NBER Working Paper 6600,

Barzel, Y., 1997, Economic Analysis of Property Rights (Cambridge University Press, Cambridge).

Bushman, R.M., R.J. Indjejikian and A. Smith, 1996, CEO Compensation: The role of individual performance evaluation, Journal of Accounting and Economics 21, 161-193.

Capelli, P. and D. Neumark, 2001, Do "High-Performance" Work Practices Improve Establishment-Level Outcomes?, Industrial and Labor Relations Review 54, 737-775.

Coughlan, A.T. and C. Narasimhan, 1992, An Empirical Analysis of Sales-Force Compensation Plans, Journal of Business 65, 93-121.

Foss, N.J. and K. Foss, 2002, Authority and Discretion: Tradeoffs, Credible Commitment, and Implications for New Organizational Forms, Unpublished paper (Dept. of Industrial Economics and Strategy, Copenhagen Business School, Copenhagen).

Freeman, C. and L.L.G. Soete, 1997, The Economics of Industrial Innovation (Pinter, London).

Gjerding, A.N., (Editor), 1997, Den fleksible virksomhed: Omstillingspres og fornyelse i dansk erhvervsliv (Erhvervsudviklingsrådet, Copenhagen).

Greene, W.H., 1997, Econometric Analysis (Prentice-Hall, Upper Saddle River, New Jersey).

Holmström, B., 1979, Moral Hazard and Observability, Bell Journal of Economics 10, 7491.

Holmström, B., 1989, Agency Costs and Innovation, Journal of Economic Behavior and Organization 12, 305-327.

Holmström, B. and P. Milgrom, 1987, Aggregation and Linearity in the Provision of Intertemporal Incentives, Econometrica 55, 303-28.

Holmström, B. and P. Milgrom, 1990, Regulating Trade Among Agents, Journal of Institutional and Theoretical Economics 146, 85-105.

Holmström, B. and P. Milgrom, 1991, Multitask Principal-Agent Analyses: Incentive Contracts, Asset Ownership, and Job Design, Journal of Law, Economics, and Organization 7, 24-52.

Jensen, M.C. and W.H. Meckling, 1992, Specific and General Knowledge and Organizational Structure, in: L. Werin and H. Wijkander (Editors), Contract Economics (Blackwell, Oxford).

John, G. and B. Weitz, 1989, Salesforce Compensation: An Empirical Investigation of Factors Related to Use of Salary Versus Incentive Compensation, Journal of Marketing Research 26, 1-14.

Lafontaine, F., 1992, Agency theory and franchising, RAND Journal of Economics 23, 263283. 
Lambert, R. and D. Larker, 1987, An analysis of the use of accounting and market measures of performance in executive compensation contracts, Journal of Accounting Research 25, $85-125$.

Laursen, K., 2002, The Importance of Sectoral Differences in the Application of Complementary HRM Practices for Innovation Performance, International Journal of the Economics of Business 9, 139-156.

Laursen, K. and N. Foss, forthcoming, New HRM Practices, Complementarities, and the Impact on Innovation Performance, Cambridge Journal of Economics

Lund, R. and A.N. Gjerding, 1996, The flexible company innovation, work organisation and human resource management, DRUID Working Paper no. 17 (IKE Group/DRUID, Department of Business Studies, Aalborg).

Mansfield, E., J. Rapoport, A. Romero, S. Villani, F. Husic and S. Wagner, 1977, The Production and Application of Industrial Technology (Norton, New York).

Martin, R.E., 1988, Franchising and Risk Management, American Economic Review 78, 954-968.

Masten, S. and S. Saussier, 2002, Econometrics of Contracts: an Assessment of Developments in the Empirical Literature on Contracting, in: E. Brousseau and J.-M. Glachant (Editors), The Economics of Contracts (Cambridge University Press, Cambridge).

Mendelson, H. and R.R. Pillai, 1999, Information Age Organizations, Dynamics, and Performance, Journal of Economic Behavior and Organization 38, 253-281.

Nelson, R.R. and S. Winter, 1982, An Evolutionary Theory of Economic Change (Harvard University Press, Cambridge, Massachusetts).

Norton, S.W., 1987, An Empirical Look at Franchising as an Organizational Form, Journal of Business 61, 197-217.

Prendergast, C., 1999, The Provision of Incentives in Firms, Journal of Economic Literature 37, 7-63.

Prendergast, C., 2000, The Tenuous Tradeoff Between Risk and Incentives, NBER Working Paper 7815,

Shelanski, H. and P.G. Klein, 1995, Empirical Research in Transaction Cost Economics: A Review and Assessment, Journal of Law, Economics and Organization 11, 335-361.

Sloan, R.G., 1992, Accounting earnings and top executive compensation, Journal of Accounting and Economics 16, 55-100. 


\title{
$D_{\text {anish }} \mathbf{R}_{\text {esearch }} \mathbf{U}_{\text {nit for }} \mathbf{I}_{\text {ndustrial }} \mathbf{D}_{\text {ynamics }}$
}

\author{
The Research Programme
}

The DRUID-research programme is organised in 3 different research themes:

\section{- The firm as a learning organisation}

- Competence building and inter-firm dynamics

- The learning economy and the competitiveness of systems of innovation

In each of the three areas there is one strategic theoretical and one central empirical and policy oriented orientation.

\section{Theme A: The firm as a learning organisation}

The theoretical perspective confronts and combines the resource-based view (Penrose, 1959) with recent approaches where the focus is on learning and the dynamic capabilities of the firm (Dosi, Teece and Winter, 1992). The aim of this theoretical work is to develop an analytical understanding of the firm as a learning organisation.

The empirical and policy issues relate to the nexus technology, productivity, organisational change and human resources. More insight in the dynamic interplay between these factors at the level of the firm is crucial to understand international differences in performance at the macro level in terms of economic growth and employment.

\section{Theme B: Competence building and inter-firm dynamics}

The theoretical perspective relates to the dynamics of the inter-firm division of labour and the formation of network relationships between firms. An attempt will be made to develop evolutionary models with Schumpeterian innovations as the motor driving a Marshallian evolution of the division of labour.

The empirical and policy issues relate the formation of knowledge-intensive regional and sectoral networks of firms to competitiveness and structural change. Data on the structure of production will be combined with indicators of knowledge and learning. IO-matrixes which include flows of knowledge and new technologies will be developed and supplemented by data from case-studies and questionnaires. 
Theme C: The learning economy and the competitiveness of systems of innovation.

The third theme aims at a stronger conceptual and theoretical base for new concepts such as 'systems of innovation' and 'the learning economy' and to link these concepts to the ecological dimension. The focus is on the interaction between institutional and technical change in a specified geographical space. An attempt will be made to synthesise theories of economic development emphasising the role of science basedsectors with those emphasising learning-by-producing and the growing knowledgeintensity of all economic activities.

The main empirical and policy issues are related to changes in the local dimensions of innovation and learning. What remains of the relative autonomy of national systems of innovation? Is there a tendency towards convergence or divergence in the specialisation in trade, production, innovation and in the knowledge base itself when we compare regions and nations?

\section{The Ph.D.-programme}

There are at present more than 10 Ph.D.-students working in close connection to the DRUID research programme. DRUID organises regularly specific Ph.D-activities such as workshops, seminars and courses, often in a co-operation with other Danish or international institutes. Also important is the role of DRUID as an environment which stimulates the Ph.D.-students to become creative and effective. This involves several elements:

- access to the international network in the form of visiting fellows and visits at the sister institutions

- participation in research projects

- access to supervision of theses

- access to databases

Each year DRUID welcomes a limited number of foreign Ph.D.-students who wants to work on subjects and project close to the core of the DRUID-research programme.

\section{External projects}

DRUID-members are involved in projects with external support. One major project which covers several of the elements of the research programme is DISKO; a comparative analysis of the Danish Innovation System; and there are several projects involving international co-operation within EU's 4th Framework Programme. DRUID is open to host other projects as far as they fall within its research profile. Special attention is given to the communication of research results from such projects to a wide set of social actors and policy makers. 


\section{DRUID Working Papers}

96-1 Lundvall, Bengt-Åke: The Social Dimension of the Learning Economy. (ISBN 87-7873-000-7)

96-2 Foss, Nicolai J.: Firms, Incomplete Contracts and Organizational Learning. (ISBN 87-7873-001-5)

96-3 Dalum, Bent and Villumsen, Gert: Are OECD Export Specialisation Patterns Sticky?' Relations to the Convergence-Divergence Debate. (ISBN 87-7873-002-3)

96-4 Foss, Nicolai J: Austrian and Post-Marshallian Economics: The Bridging Work of George Richardson. (ISBN 87-7873-003-1)

96-5 Andersen, Esben S., Jensen, Anne K., Madsen, Lars and Jørgensen, Martin: The Nelson and Winter Models Revisited: Prototypes for ComputerBased Reconstruction of Schumpeterian Competition. (ISBN 87-7873-005-8)

96-6 Maskell, Peter: Learning in the village economy of Denmark. The role of institutions and policy in sustaining competitiveness. (ISBN 87-7873-006-6)

96-7 Foss, Nicolai J. \& Christensen, Jens Frøslev: A Process Approach to Corporate Coherence. (ISBN 87-7873-007-4)

96-8 Foss, Nicolai J.: Capabilities and the Theory of the Firm. (ISBN 87-7873008-2)

96-9 Foss, Kirsten: A transaction cost perspective on the influence of standards on product development: Examples from the fruit and vegetable market. (ISBN 87-7873-009-0)

96-10 Richardson, George B.: Competition, Innovation and Increasing Returns. (ISBN 87-7873-010-4)

96-11 Maskell, Peter: Localised low-tech learning in the furniture industry. (ISBN 87-7873-011-2)

96-12 Laursen, Keld: The Impact of Technological Opportunity on the Dynamics of Trade Performance. (ISBN 87-7873-012-0) 
96-13 Andersen, Esben S.: The Evolution of an Industrial Sector with a Varying Degree of Roundaboutness of Production. (ISBN 87-7873-013-9)

96-14 Dalum, Bent, Laursen, Keld \& Villumsen, Gert: The Long Term Development of OECD Export Specialisation Patterns: De-specialisation and "Stickiness". (ISBN 87-7873-014-7)

96-15 Foss, Nicolai J.: Thorstein B. Veblen: Precursor of the Competence-Based Approach to the Firm. (ISBN 87-7873-015-5)

96-16 Gjerding, Allan Næs: Organisational innovation in the Danish private business sector. (ISBN 87-7873-016-3)

96-17 Lund, Reinhard \& Gjerding, Allan Nas: The flexible company Innovation, work organisation and human ressource management. (ISBN 87-7873-017-1)

97-1 Foss, Nicolai J.: The Resource-Based Perspective: An Assessment and Diagnosis of Problems. (ISBN 87-7873-019-8)

97-2 Langlois, Richard N. \& Foss, Nicolai J.: Capabilities and Governance: the Rebirth of Production in the Theory of Economic Organization. (ISBN 877873-020-1)

97-3 Ernst, Dieter: Partners for the China Circle? The Asian Production Networks of Japanese Electronics Firms. (ISBN 87-7873-022-8)

97-4 Richardson, George B.: Economic Analysis, Public Policy and the Software Industry. (ISBN 87-7873-023-6)

97-5 Borrus, Michael \& Zysman, John: You Don't Have to Be A Giant: How The Changing Terms of Competition in Global Markets are Creating New Possibilities For Danish Companies. (ISBN 87-7873-024-4)

97-6 Teubal, Morris.: Restructuring and Embeddeness of Business EnterprisesTowards an Innovation System Perspective on Diffusion Policy. (ISBN 877873-025-2)

97-7 Ernst, Dieter \& Guerrieri, Paolo: International Production Networks and Changing Trade Patterns in East Asia: The case of the Electronics Industry. (ISBN 87-7873-026-0)

97-8 Lazaric, Nathalie \& Marengo, Luigi: Towards a Characterisation of Assets and Knowledge Created in Technological Agreements: Some evidence from the automobile-robotics sector. (ISBN 87-7873-027-9) 
97-9 Ernst, Dieter.: High-Tech Competition Puzzles. How Globalization Affects Firm Behavior and Market Structure in the Electronics Industry. (ISBN 877873-028-7)

97-10 Foss, Nicolai J.: Equilibrium vs Evolution in the Resource-Based Perspective: The Conflicting Legacies of Demsetz and Penrose. (ISBN 877873-029-5)

97-11 Foss, Nicolai J.: Incomplete Contracts and Economic Organisation: Brian Loasby and the Theory of the firm. (ISBN 87-7873-030-9)

97-12 Ernst, Dieter \& Lundvall, Bengt-Åke: Information Technology in The Learning Economy - Challenges for Developing Countries. (ISBN 87-7873031-7)

97-13 Kristensen, Frank Skov (p): A study of four organisations in different competitive environments. (ISBN 87-7873-032-5)

97-14 Drejer, Ina, (p) Kristensen, Frank Skov (p) \& Laursen, Keld (p): Studies of Clusters as a Basis for Industrial and Technology Policy in the Danish Economy. (ISBN 87-7873-033-3)

97-15 Laursen, Keld (p) \& Drejer, Ina (p): Do Inter-sectoral Linkages Matter for International Export Specialisation? (ISBN 87-7873-034-1)

97-16 Lundvall, Bengt-Åke \& Kristensen, Frank Skov (p): Organisational change, innovation and human resource Development as a response to increased competition. (ISBN 87-7873-036-8)

98-1 Prast, Mette (p): An Empirical Model of Firm Behaviour: A dynamic Approach to Competence Accumulation and Strategic Behaviour. (ISBN 877873-037-6)

98-2 Ducatel, Ken: Learning and skills in the Knowledge Economy. (ISBN 877873-038-4)

98-3 Ernst, Dieter: What Permits Small Firms to Compete in High-Tech Industries? Inter-Organizational Knowledge Creation in the Taiwanese Computer Industry. (ISBN 87-7873-039-2)

98-4 Christensen, Jens Frøslev: The Dynamics of the Diversified Corporation and the Role of Central Management of Technology. (ISBN 87-7873-040-6)

98-5 Valente, Marco (p): Laboratory for Simulation Development. (ISBN 877873-041-4)

98-6 Valente, Marco (p): Technological Competition: a Qualitative Product Life 
Cycle. (ISBN 87-7873-042-2)

98-7 Lam, Alice: The Social Embeddedness of Knowledege: Problems of Knowledge Sharing and Organisational Learning in International HighTechnology Ventures. (ISBN 87-7873-043-0)

98-8 Jørgensen, Kenneth M. (p): Information Technology and Change in Danish Organizations. (ISBN 87-7873-044-9)

98-9 Andersen, Esben Sloth: Escaping Satiation in an Evolutionary Model of Structural economic Dynamics. (ISBN 87-7873-045-7)

98-10 Foss, Kirsten: Technological Interdependencies, Specialization and Coordination: A Property Rights Perspective on The Nature of the Firm. (ISBN 87-7873-046-5)

98-11 Andersen, Poul H: Organizing International Technological Collaboration in Subcontractor Relationships. An Investigation of the Knowledge-Stickyness Problem. (ISBN 87-7873-047-3)

98-12 Nymark, Søren (p): Billeder af strategi i forandringsrige organisatoriske omgivelser: 3 cases fra DISKO studierne. (ISBN 87-7873-048-1)

98-13 Andersen, Esben Sloth: The Evolution of the Organisation of Industry. (ISBN 87-7873-050-3)

98-14 Foss, Kirsten \& Foss, Nicolai J.: The Market Process and The Firm: Toward a Dynamic Property Rights Perspective. (ISBN 87-7873-051-1)

98-15 Lorenz, Edward: Societal Effects and the Transfer of Business Practices to Britain and France. (ISBN 87-7873-053-8)

98-16 Ernst, Dieter: Catching-Up, Crisis and Industrial Upgrading. Evolutionary Aspects of Technological Learning in Korea's Electronics Industry. (ISBN 87-7873-054-6)

98-17 Kaisla, Jukka (p): The Market Process and the Emergence of the Firm: Some Indications of Entrepreneurship Under Genuine Uncertainty. (ISBN 87-7873-055-4)

98-18 Laursen, Keld (p): Do Export and Technological Specialisation Patterns Co-evolve in Terms of Convergence or Divergence?: Evidence from 19 OECD Countries, 1971-1991. (ISBN 87-7873-056-2)

98-19 Foss, Nicolai J.: Firms and the Coordination of Knowledge: Some Austrian Insights. (ISBN 87-7873-057-0)

98-20 Mahnke, Volker (p) \& Aadne, John Harald: Process of Strategic Renewal, Competencies, and the Management of Speed. (ISBN 87-7873-058-9) 
98-21 Lorenzen, Mark (p): Information, cost learning, and trust. Lessons form cooperation and higher-order capabilities amongst geographically proximate firms. (ISBN 87-7873-059-7)

98-22 Lam, Alice: Tacit Knowledge, Organisational Learning and Innovation: A Societal Perspective. (ISBN 87-7873-060-0)

98-23 Lund, Reinhard: Organizational and innovative flexibility mechanisms and their impact upon organizational effectiveness. (ISBN 87-7873-061-9)

98-24 Christensen, Jesper Lindgaard \& Drejer, Ina (p): Finance and Innovation System or Chaos. (ISBN 87-7873-062-7)

98-25 Laursen, Keld (p): How Structural Change Differs, and Why it Matters (for Economic Growth) (ISBN 87-7873-063-5)

98-26 Holmén, Magnus \& Jacobsson, Staffan: A method for identifying actors in a knowledge based cluser. (ISBN 87-7873-064-3)

98-27 Richardson, G. B.: Production, Planning and Prices. (ISBN 87-7873-065-1)

98-28 Foss, Nicolai J.: Austrian Economics and Game Theory: a Preliminary Methodological Stocktaking. (ISBN 87-7873-067-8)

98-29 Foss, Nicolai J. \& Mahnke, Volker (p): Strategy Research and the Market Process Perspective. (ISBN 87-7873-068-6)

98-30 Laursen, Keld (p): Revealed Comparative Advantage and the Alternatives as Measures of International Specialisation. (ISBN 87-7873-069-4)

99-1 Lorenz, E.: Organisationaal Innovation, Governance Structure and Innovative Capacity In British and French Industry. (ISBN 87-7873-070-8)

99-2 Ernst, Dieter: Responses to the Crisis: Constraints to a Rapid Trade Adjustment in East Asia's Electronics Industry. (ISBN 87-7873-071-6)

99-3 Foss, N. J. : Understanding Leadership: A Coordination Theory. (ISBN 877873-072-4)

99-4 Foss, K \& Foss, N. J: Understanding Ownership: Residual Rights of Control and Appropriable Control Rights. ( ISBN 87-7873-073-2)

99-5 Foss, K \& Foss, N. J: Organizing Economic Experiments: The role of Firms. (ISBN 87-7873-075-9)

99-6 Jorgensen Kenneth. M. (p) : The Meaning og Local Knowledges. (ISBN 87-7873-076-7)

99-7 Foss, N. J.: Capabilities, Confusion, and the Costs of Coordination: On Some Problems in Recent Research On Inter-Firm Relations. (ISBN87-7873- 
$077-5)$

99-8 Lund, Reinhard: Tillidsrepræsentantsystemet og de

fleksiblevirksomhedsformer. Juli 1999. (ISBN887-7873-078-3)

99-9 Nymark, Søren: Organisatorisk læring gennem den værdibaserede organisations fortællinger. (ISBN 87-7873-079-1)

99-10 Laursen, K. \& Meliciani, V.: The importance of technology based intersectoral linkages for market share dynamics. (ISBN 87-7873-080-5)

99-11 Laursen, K., Mahnke, V., Vejrup-Hansen, P.: Firm growth from a knowlegde structure perspective. ( ISBN 87-7873-081-3)

99-12 Lundvall, Bengt-Åke, Christensen, Jesper. L.: Extending and Deepening the Analysis of Innovation Systems - with Emperical Illustrations from the DISCO-project. (ISBN 87-7873-082-1)

00-1 Llerena, Patrick \& Oltra, Vanessa: Diversity of innovative strategy as a source technological performance. (ISBN 87-7873-085-6)

00-2 Llerena, Patrick \& Mireille Matt: Technology policy and cooperation: A paradigmatic approach. (ISBN 87-7873-086-4)

00-3 Cusmano, Lucia: Technology Policy and Co-operative R\&D: the role of relational research capacity. (ISBN 87-7873-087-2)

00-4 Mikkola, Juliana Hsuan: Modularization assessment of product architecture. (ISBN87-7873-088-0)

00-5 Yvrande, Anne: The new British railways structure: A transaction cost economics analysis. (ISBN87-7873-089-9)

00-6 Dijk, Machiel van \&Nomaler Önder: Technological diffusion patterns and their effects on industrial dynamics. (ISBN 87-7873-090-2)

00-7 Storper, Michael \& Chen, Yun-chung with De Paolis, Fernando: The Effects of Globalization on Location of Industries in the OECD and European Union (ISBN87-7873-091-0)

00-8 Sanders, Mark \& Weel, Bas ter : Skill-Biased Technical Change: Theoretical Concepts, Empirical Problems and a Survey of the Evidence (ISBN87-7873-092-9)

00-9 Tomlinson, Mark: Innovation surveys: A researcher's perspective (ISBN87-7873-093-7)

00-10 Nymark, Søren: Value-based management in learning organizations through 'hard' and 'soft' managerial approaches: The case of Hewlett-Packard 
(ISBN87-7873-094-5)

00-11 Yoguel, Gabriel; Novick, Marta \& Marin, Anabel: Production Networks: Linkages, Innovation Processes and Social Management Technologies (ISBN87-7873-095-3)

00-12 Yoguel, Gabriel \& Boscherini, Fabio: The environment in the development of firms' innovative capacities: Argentine industrial SMEs from different local systems (ISBN87-7873-096-1)

00-13 Arocena, Rodrigo \& Sutz, Judith: Interactive Learning Spaces and Development Policies in Latin America (ISBN87-7873-098-8)

01-01 Mathews, John A.: Competitive Interfirm Dynamics within an Industrial Market System ( ISBN87-7873-099-6)

01-02 Giarratana, Marco \& Torrisi, Salvatore: Competence accumulation and collaborative ventures: Evidence from the largest European electronics firms and implications for the EU technological policies (ISBN 87-7873-100-3)

01-03 Nemirovsky, Adolfo \& Yoguel, Gabriel: Dynamics of high-technology firms in the Silicon Valley (ISBN 87-7873-101-1)

01-04 Castellacci, Fulvio: A 'technology-gap approach to cumulative growth': toward an integrated model. Empirical evidence for Spain, 1960-1997 (ISBN 87-7873-103-8)

01-05 Nuvolari. Alessandro: Collective invention during the British industrial revolution: The case of the Cornish pumping engine (ISBN 87-7873-104-6)

01-06 Costa, Ionara: Ownership and technological capabilities in Brazil (ISBN 877873-105-4)

01-07 Foss, Nicolai J.: Economic organization in the knowledge economy: some austrian insights (ISBN 87-7873-106-2)

01-08 Cantwell, John \& Kosmopoulou, Elena: Determinants of internationalisation on corporate technology (ISBN 87-7873-107-0)

01-09 Loasby, Brian: Industrial dynamics. Why connection matter (ISBN 87-7873108-9)

01-10 Jeppesen, Lars Bo: Making Consumer Knowledge Available and useful (877873-109-7)

01-11 Laursen, Keld: The Importance of Sectoral Differences in the Application of (Complementary) HRM Practices for Innovation Performance (87-7873-1100) 
01-12 Johnson, Björn \& Segura-Bonilla, Olman: Innovation Systems and Developing Countries: Experience from the SUDESCA Project (87-7873-1119)

01-13 Foss, Nicolai J. : Bounded Rationality in the Economics of Organization: Present Use and (Some) Future Possibilities (87-7873-112-7)

01-14 Reichstein, Toke \& Dahl, Michael S.: Patterns and Dependencies of Firm Growth (87-7873-113-5)

01-15 Foss, Nicolai J. : The Problem With Bounded Rationality: On Behavioral Assumptions in the Theory of the Firm (87-7873-114-3)

01-16 Foss, Nicolai J. : Selective Intervention and Internal Hybrids: Interpreting and learning from the Rise and Decline of the Oticon Spaghetti Organization (877873-115-1)

02-01 Foss, Kirsten; Foss, Nicolai; Klein, Peter G. \& Klein, Sandra K.: Heterogeneous Capital, Entrepreneurship, and Economic Organization (877873-117-8)

02-02 Foss, Kirsten \& Foss, Nicolai J.: Creating, Capturing and Protecting Value: A Property Rights-based View of Competitive Strategy (87-7873-118-6)

02-03 Laursen, Keld \& Salter, Ammon: The Fruits of Intellectual Production: Economic and Scientific Specialisation Among OECD Countries (87-7873119-4)

02-04 Foss, Nicolai J.: The Strategy and Transaction Cost Nexus: Past Debates, Central Questions, and Future Research Possibilities (87-7873-120-8)

02-05 Arocena, Rodrigo \& Sutz, Judith: Innovation Systems and Developing Countries (87-7873-121-6)

02-06 Lundvall, Bengt-Åke: The University in the Learning Economy (87-7873122-4)

02-07 Tomlinson, Mark: The Academic Robotics Community in the UK: Web based data construction and analysis of a distributed community of practice $(87-7873-123-2)$

02-08 Lorenzen, Mark \& Mahnke, Volker: Global Strategy and the Acquisition of Local Knowledge: How MNCs Enter Regional Knowledge Cluster (87-7873124-0)

02-09 Drejer, Ina: A Schumpeterian Perspective on Service Innovation (87-7873125-9)

02-10 Dalum, Bent; Pedersen, Christian Ø.R. \& Villumsen, Gert: Technological Life Cycles: Regional Clusters Facing Disruption (87-7873-126-7) 
02-11 Foss, Kirsten \& Foss, Nicolai J.: Authority and Discretion: Tensions. Credible Delegation and Implications for New Organizational Forms (877378-157-5)

02-12 Bathelt, Harald; Malmberg, Anders \& Maskell, Peter: Clusters and Knowledge: Local Buzz, Global Pipelines and the Process of Knowledge Creation (87-7873-128-3)

02-13 Mahnke, Volker \& Venzin, Markus: How do digital information good characteristics influence pace and modalities of international market entry? (87-7873-129-1)

02-14 Foss, Nicolai J. \& Laursen, Keld: Performance Pay, Delegation, and Multitasking under Uncertainty and Innovativeness: An Empirical Investigation (87-7873-130-5)

All correspondence concerning the DRUID Working Papers should be send to:

$$
\begin{gathered}
\text { Aalborg University } \\
\text { Jeanette Hvarregaard } \\
\text { Fibigerstræde } 4 \\
\text { DK-9220 Aalborg OE }
\end{gathered}
$$

Tel. 4596358265

Fax. 4598156013

E-mail: druid-wp@business.auc.dk 